\title{
Atmospheric methanol measurement using selective catalytic methanol to formaldehyde conversion
}

\author{
S. J. Solomon ${ }^{1}$, T. Custer ${ }^{1}$, G. Schade ${ }^{1,3}$, A. P. Soares Dias ${ }^{2}$, and J. Burrows ${ }^{1}$ \\ ${ }^{1}$ Institute of Environmental Physics, University of Bremen, Bremen, Germany \\ ${ }^{2}$ GRECAT-Grupo de Estudos de Catalise Heterogenea, Universidade Tecnica de Lisboa, Lisbon, Portugal \\ ${ }^{3}$ presently with: Department of Atmospheric Sciences, Texas A\&M University, Texas, USA
}

Received: 16 February 2005 - Published in Atmos. Chem. Phys. Discuss.: 31 May 2005

Revised: 30 September 2005 - Accepted: 12 October 2005 - Published: 24 October 2005

\begin{abstract}
A novel atmospheric methanol measurement technique, employing selective gas-phase catalytic conversion of methanol to formaldehyde followed by detection of the formaldehyde product, has been developed and tested. The effects of temperature, gas flow rate, gas composition, reactor-bed length, and reactor-bed composition on the methanol conversion efficiency of a molybdenum-rich, ironmolybdate catalyst [Mo-Fe-O] were studied. Best results were achieved using a 1:4 mixture $(\mathrm{w} / \mathrm{w})$ of the catalyst in quartz sand. Optimal methanol to formaldehyde conversion ( $>95 \%$ efficiency) occurred at a catalyst housing temperature of $345^{\circ} \mathrm{C}$ and an estimated sample-air/catalyst contact time of $<0.2$ seconds. Potential interferences arising from conversion of methane and a number of common volatile organic compounds (VOC) to formaldehyde were found to be negligible under most atmospheric conditions and catalyst housing temperatures. Using the new technique, atmospheric measurements of methanol were made at the University of Bremen campus from 1 to 15 July 2004. Methanol mixing ratios ranged from 1 to $5 \mathrm{ppb}$ with distinct maxima at night. Formaldehyde mixing ratios, obtained in conjunction with methanol by periodically bypassing the catalytic converter, ranged from 0.2 to $1.6 \mathrm{ppb}$ with maxima during midday. These results suggest that selective, catalytic methanol to formaldehyde conversion, coupled with existing formaldehyde measurement instrumentation, is an inexpensive and effective means for monitoring atmospheric methanol.
\end{abstract}

Correspondence to: S. J. Solomon

(juliet@iup.physik.uni-bremen.de)

\section{Introduction}

Methanol mixing ratios between 1 and $20 \mathrm{ppb}$ are commonly observed in the planetary boundary layer (Heikes et al., 2002), often making it the second most abundant organic trace gas after methane. Methanol can play an important role in upper tropospheric photooxidant chemistry via its contribution to the $\mathrm{HO}_{\mathrm{x}}$ budget after its oxidation to formaldehyde (Tie et al., 2003; Singh et al., 1995, 2000, 2004). Several studies have reported and discussed methanol mixing ratios in the troposphere (Kelly et al., 1993; Goldan et al., 1995a, b, 1997; Lamanna and Goldstein, 1999; Holzinger et al., 2001; Schade and Goldstein, 2001; Karl et al., 2001, 2003; Singh et al., 1995, 2000, 2004). Atmospheric sources and sinks of methanol have been discussed in four recent publications by Galbally and Kirstine (2002), Heikes et al. (2002), Tie et al. (2003), and Singh et al. (2004). Although the groundwork for understanding the global cycling of methanol has been laid, the distribution and magnitude of sources and sinks and environmental factors affecting them are still uncertain. More experimental measurements of methanol are needed to improve our knowledge of methanol production and processing in the environment.

Measurements of atmospheric methanol have been made using a variety of techniques under various circumstances. Techniques include photoacoustic spectroscopy (PAS) (Repond and Sigrist, 1996 ; Prasad and Thakur, 2003), Fourier transform infrared spectroscopy (FTIR) (Yokelson et al., 1997, 2003), pre-concentration followed by gas or liquid chromatography (Snider and Dawson, 1985; Goldan et al., 1995a, b; Riemer et al., 1998; Lamanna and Goldstein, 1999; Nguyen et al., 2000; Schade and Goldstein, 2001; Kesselmeier et al., 2002; Millet et al., 2004; Singh et al., $1995,2000,2004)$, and chemical ionisation mass spectrometry (CIMS) (Lindinger et al., 1998; Holzinger et al., 2001;

(C) 2005 Author(s). This work is licensed under a Creative Commons License. 
de Gouw et al., 2000, 2003; Karl et al., 2001, 2003). In spite of this impressive array of tools, the experimental measurement of methanol at typical tropospheric abundances can still be quite challenging. While photoacoustic spectrometers can be field portable and run unattended for long periods of time, they lack sensitivity to measure methanol at relevant concentrations in much of the troposphere. A similar situation holds for FTIR, which requires a very long path length in order to achieve useful limits of detection. Methods designed to preconcentrate/trap methanol, such as carbon-based adsorption cartridges, exhibit low trapping efficiency compared to other VOCs (Qin et al., 1997). While gas or liquid chromatography can readily separate methanol from other species, detection of the methanol following separation can be inefficient. For example, gas chromatographic flame ionisation detectors (GC-FID) show poor response for methanol compared to other VOCs (Lamanna and Goldstein, 1999). CIMS, while sensitive and selective for methanol (de Gouw et al., 2003), is still quite expensive and not yet easily field transportable. Methods that will improve sensitivity, portability, and cost of ambient methanol mixing ratio measurements are clearly desirable.

A variety of measurement techniques also exist for the measurement of formaldehyde and are reviewed in Kleindienst et al. (1988), Vairavamurthy et al. (1992), and briefly in Clemitshaw (2004). Intercomparisons among various formaldehyde detection methods have also been carried out in Gilpin et al. (1997) and Cárdenas et al. (2000). Although formaldehyde can also be a challenge to analyse, over the last 20 years high quality measurements of formaldehyde have been established using wet-chemical techniques (Dong and Dasgupta, 1986, 1987; Fan and Dasgupta, 1994; Heikes et al., 1996; Dasgupta et al., 1988, 1998, 1999; $\mathrm{Li}$ et al., 2001). Such instruments are relatively inexpensive, have a detection limit in the mid-ppt (parts per trillion) range, are commercially available, run essentially continuously, and are highly selective for formaldehyde. It would be a clear advantage if these techniques were adaptable to the measurement of methanol. In the chemical industry, oxidative dehydrogenation of methanol to formaldehyde is key to the manufacture of formaldehyde (Gerberich et al., 1980). Methanol to formaldehyde conversion is accomplished by passing methanol vapour in air over a heated, chemically selective catalyst and collecting the resulting formaldehyde product from the exhaust stream. Using the same process for atmospheric measurements, if gas-phase methanol in the troposphere can efficiently and selectively be converted to formaldehyde, then capabilities of existing atmospheric formaldehyde measurement instrumentation can be expanded, simply and at low cost, to include methanol.

We tested the performance of a selective methanol to formaldehyde catalytic converter for atmospheric methanol measurements. Optimum temperature, flow rate, catalyst bed composition, and air/catalyst contact times were determined for this portable catalytic converter interfaced with a com- mercial formaldehyde measurement device. Potential interferences due to catalytic conversion of methane and several VOCs to formaldehyde were also examined and finally, real air samples were used to demonstrate the feasibility of the method.

\section{Experimental}

\subsection{Catalytic converter}

\subsubsection{Catalyst}

All of the iron molybdate catalyst used for this study was prepared in laboratories at the Universidade Tecnica de Lisboa, Portugal and a full description of its preparation and characterisation is given elsewhere (Soares et al., 2001, 2003). Briefly, the molybdenum (Mo) rich iron molybdate catalyst (atomic ratio $\mathrm{Mo} / \mathrm{Fe}=3 ; \mathrm{Fe}_{2}\left(\mathrm{MoO}_{4}\right)_{3} \cdot 3 \mathrm{MoO}_{3}$ ) was coprecipitated from aqueous solutions of iron nitrate and ammonium heptamolybdate. The yellow-green precipitate was ripened in contact with mother liquors at $373 \mathrm{~K}$ for $3 \mathrm{~h}$. Finally, the precipitate is filtered, dried at $393 \mathrm{~K}$ overnight and calcinated. Calcinations were performed at $648 \mathrm{~K}$ for $10 \mathrm{~h}$ in a flow of air.

\subsubsection{Reactor}

The reactor constructed for catalytic conversion of gas-phase methanol to formaldehyde consisted of a stainless steel tube $15 \mathrm{~cm}$ in length and having $\sim 1 \mathrm{~cm}$ ID (inner diameter) and $\sim 1.27 \mathrm{~cm}$ OD (outer diameter) embedded in a heated aluminium block. The tube, through which sample air was passed, was partially filled with a catalyst bed consisting of a mixture by weight of iron molybdate catalyst and quartz sand $(0.5 \mathrm{~mm}$ average grain diameter). The quartz sand served as an inert substrate that evenly distributes the catalyst and that allows the sample air to flow evenly across the diameter of the tube, thereby increasing catalyst/methanol contact. The catalyst bed, filling various fractions of the total tube length, was held in place at the middle of the tube by filling the remainder with glass beads and glass wool. The ends of the tube were then fixed using $\frac{1}{2}$ " to $\frac{1}{4}$ " swagelok reducing unions. The aluminium block for the reactor bed was heated with a commercial cartridge heater with embedded thermocouple (350 W, Ihne \& Tesch HPS 10D, 100L). The temperature of the block was maintained using an electronic temperature controller (TC-Direct, Germany). The catalyst assembly was surrounded by Silcapor ultra 100-23 insulation and placed inside a metal box.

\subsection{Formaldehyde detection}

A commercial, wet-chemical formaldehyde measurement instrument (Alpha Omega Power Technologies, Model MA100) was employed for all measurements and is hereafter 


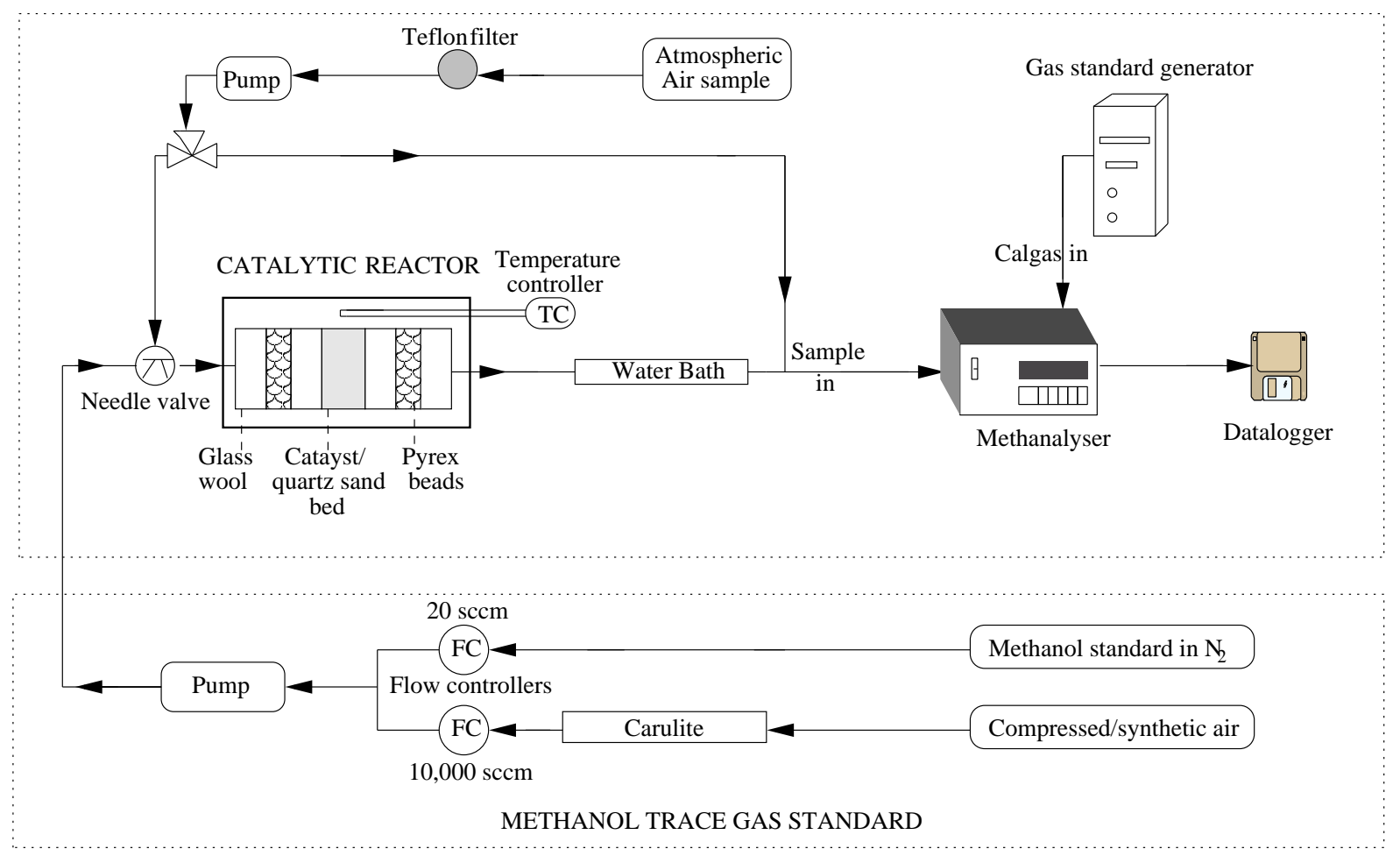

Fig. 1. Schematic diagram of the experimental setup for catalytic converter calibration and air sampling.

referred to as the methanalyser. A more thorough description of this and related instruments are given in ( $\mathrm{Li}$ et al., 2000; Fan and Dasgupta, 1994). This particular instrument consists of a Nafion-membrane diffusion scrubber integrated with an automated, liquid reactor. Air is passed through the scrubber at a constant flow of $1 \mathrm{~L} \mathrm{~min}^{-1}$ and formaldehyde in the air diffuses through the membrane into a counter-flow of water. Formaldehyde in the water is then transferred continuously to the liquid reactor where it is combined with 2,4-pentanedione reagent and ammonium acetate buffer. The ensuing Hanztsch reaction with formaldehyde leads to a strongly UV-absorbent dihydropyridine product, which is continuously monitored via its fluorescence.

For these experiments, the scrubbing water and all reactor solutions were prepared using high purity Millipore water. Analytical grade 2,4-pentanedione, ammonium acetate, and glacial acetic acid were purchased from ALDRICH, Germany and used without further purification. Solutions for the methanalyser were prepared according to specifications provided by the instrument manufacturer.

\subsection{Calibration and air sampling}

\subsubsection{Permeation source}

A KIN-TEK (LaMarque, Texas, USA) gas standard generator was used to generate a trace formaldehyde standard with mixing ratios between 2 and $20 \mathrm{ppb}$ used to cal- ibrate the response of the methanalyser to formaldehyde (Fig. 1). A permeation tube (VICI Metronic), rated to release $12 \mathrm{ng} \mathrm{min}^{-1} \pm 15 \%$ formaldehyde was maintained at $50^{\circ} \mathrm{C}$ under a steady flow of $\mathrm{N}_{2}$ gas. The quoted permeation rate was further verified by periodic weightings and revealed a loss of mass over time of $11.4 \pm 0.2 \mathrm{ng} \mathrm{min}^{-1}$, in good agreement with the quoted value. Output of the permeation source, diluted by $\mathrm{N}_{2}$ gas, was fed to the calibration gas port of the methanalyser for periodic sampling or could be fed directly to the sample inlet of the methanalyser.

\subsubsection{Methanol standard}

Trace methanol mixing ratios were produced by dilution of a standard of methanol in $\mathrm{N}_{2}$ having a certified concentration of $20.4 \mathrm{nmol} \mathrm{mol}{ }^{-1}$ (Messer Griesheim, Germany). Diluting gas was either compressed air or a high purity $\mathrm{O}_{2} / \mathrm{N}_{2}$ mixture first passed through a cartridge containing an oxidation catalyst ( $\frac{1}{8}$ ", Carulite 200, Carus Chemical Company) to remove formaldehyde impurities from the gas stream. Standard tank and dilution gas flow rates were controlled using appropriate mass flow controllers from MKS instruments.

\subsubsection{Air sampling}

Ambient air was sampled at approximately $1.6 \mathrm{~L} \mathrm{~min}^{-1}$ through a $2 \mathrm{~m}$ long $0.63 \mathrm{~cm}$ OD PFA Teflon line using a Teflon pump (KNF Model N86 KTDC B). The pump air 


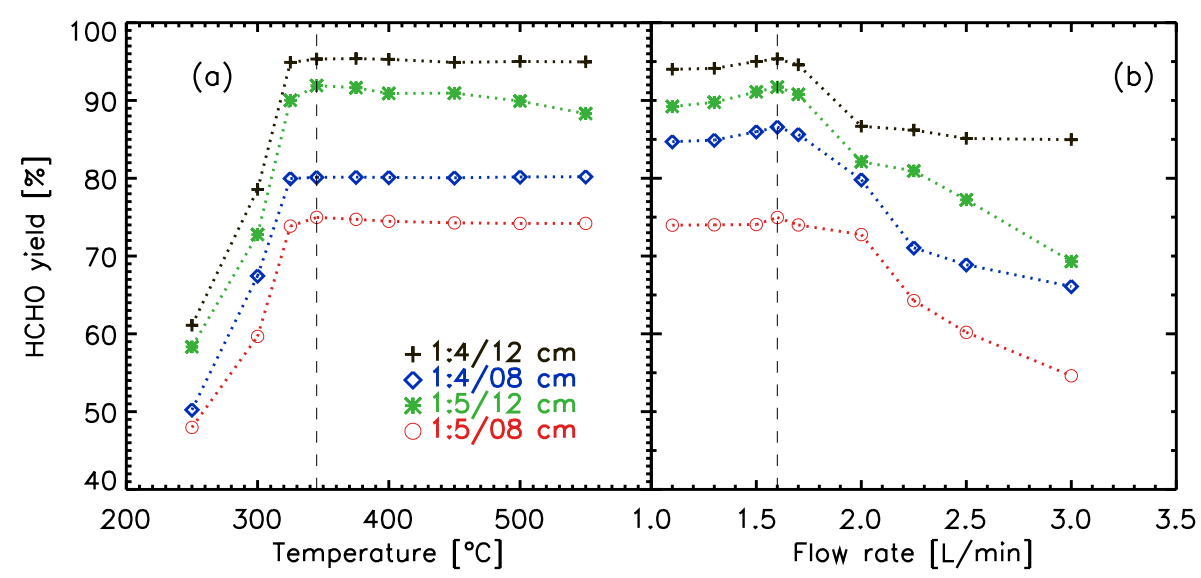

Fig. 2. (a) Formaldehyde yield as a function of catalyst housing temperature $\left({ }^{\circ} \mathrm{C}\right)$ using combinations of two different catalyst mixtures and catalyst bed lengths $(\mathrm{cm})$. The selected temperature range was $250^{\circ} \mathrm{C}$ to $550^{\circ} \mathrm{C}$. (b) Formaldehyde yield as a function of flow rate of methanol mixture through the catalytic converter. The catalyst housing temperature was regulated to an optimal $345^{\circ} \mathrm{C}$ in all four cases. The vertical dashed lines represent $345^{\circ} \mathrm{C}$ or $1.6 \mathrm{~L} \mathrm{~min}^{-1}$.

output could be automatically diverted, using a 3-way PFA Teflon valve (Metron Technologies, Germany), to pass either through or around the catalytic converter. For methanol measurement, air was pushed through the heated catalyst bed, cooled, and the effluent sub-sampled at $1 \mathrm{~L} \mathrm{~min}^{-1}$ into the methanalyser. For formaldehyde measurement, the valve was switched so that sampled air bypassed the catalytic converter and again was sub-sampled at $1 \mathrm{~L} \mathrm{~min}^{-1}$ into the methanalyser. The output of the methanalyser instrument was collected using a PCMCIA data collection card (NI DAQ 6024E, National Instruments Inc.) installed in a portable computer and controlled using a custom Lab View 6.1 programme. Timing of valve switching was also coordinated by the Lab View programme.

\subsubsection{Air residence time and cooling}

Under optimum conditions, the catalyst/quartz sand mixture filled $12 \mathrm{~cm}$ of the tubing or a volume of $\sim 9.4 \mathrm{~cm}^{3}$. Of this volume the sand/catalyst mixture itself occupies approximately half as calculated from the density of quartz $\left(\sim 2.7 \mathrm{~g} \mathrm{~cm}^{-3}\right)$ and the mass of sand/catalyst mixture added $(\sim 13.0 \mathrm{~g})$. Using this interstitial air volume and sample airflow of $1.6 \mathrm{~L} \mathrm{~min}^{-1}$ yields an estimated air/catalyst contact time of less than $0.2 \mathrm{~s}$. Although this residence time is short, at high flow rates, sample air is quite hot upon exit from the catalytic converter. High air temperatures negatively affected the performance of the methanalyser instrument for formaldehyde detection. Therefore, hot effluent was first sent through $41 \mathrm{~cm}$ of a $0.63 \mathrm{~cm}$ OD stainless steel tubing immersed in a container filled with non-circulating water. Increased radiative cooling due to this bath was sufficient to cool the air to a temperature of approximately $40^{\circ} \mathrm{C}$ prior to sampling by the methanalyser.

\section{Results and discussion}

\subsection{Catalyst characterisation}

\subsubsection{Conversion efficiency}

For this methanol monitoring scheme, it is important that methanol be quantitatively converted to formaldehyde and that none of the formaldehyde product be lost en-route to the formaldehyde detector. The efficiency or yield of the reactor, defined here as the ratio of the number of moles of formaldehyde detected to the number of moles of methanol entering the catalytic converter, needs to be as close as possible to 1 in order to provide maximum sensitivity for a measurement of atmospheric methanol. Among other factors, the catalyst bed temperature, the number of moles of catalyst accessible for conversion, the number of moles of methanol present in sample air, air/catalyst contact time and composition of the gas passed through the converter all influence conversion efficiency.

\subsubsection{Effects of reaction temperature, flow rate, and cata- lyst mass}

Figure 2a depicts catalyst conversion efficiency as a function of the temperature of the reaction bed housing for two different catalyst/quartz sand mixtures and for two different bed lengths of these mixtures. For these experiments, the methanol standard was diluted with compressed air to a methanol mixing ratio of $10.5 \pm 0.04 \mathrm{nmol} \mathrm{mol}^{-1}$ and sub-sampled through the catalytic converter at a flow rate of $\sim 1.6 \mathrm{~L} \mathrm{~min}^{-1}$. While sampling this methanol standard, the temperature of the catalyst bed housing was systematically changed and the resulting formaldehyde concentrations observed with the methanalyser. For both 1:4 and 
1:5 catalyst/quartz sand mixtures and both 8 and $12 \mathrm{~cm}$ bed lengths, a broad maximum of conversion efficiencies was observed for catalytic converter temperatures between 325 and $440^{\circ} \mathrm{C}$. This result is consistent with previous studies (Soares et al., 2001; Chu et al., 1997). Increasing the catalyst bed length from 8 to $12 \mathrm{~cm}$, using a 1:5 catalyst/quartz sand mixture, increased the efficiency in this temperature range from approximately $75 \%$ to $80 \%$. With all other variables being constant, the increase in bed length increased the catalyst/sample interaction time and showed the expected efficiency increase. Further improvement, with an ultimate efficiency greater than $95 \%$, was achieved for a 1:4 catalyst/quartz sand mixture and $12 \mathrm{~cm}$ catalyst bed length. Thus, increasing the amount of catalyst accessible for conversion also showed the expected increase in conversion efficiency.

Methanol conversion efficiency was also examined as a function of gas flow rate through the catalytic converter as this parameter directly affects the catalyst/sample interaction time and therefore efficiency. In these experiments, methanol standard gas flow rate through the catalytic converter was varied while maintaining a constant methanol mixing ratio of $10.5 \pm 0.04 \mathrm{nmol} \mathrm{mol}^{-1}$ and a constant catalytic converter housing temperature of $345^{\circ} \mathrm{C}$. The results are shown in Fig. 2b. Maximum conversion efficiency was $91 \pm 0.1 \%$ and $95 \pm 0.1 \%$ for the $1: 5$ and $1: 4$ mixtures respectively at $1.6 \mathrm{~L} \mathrm{~min}^{-1}$. Methanol to formaldehyde conversion efficiency varied little at low flow rates, but decreased suddenly as flow rates exceeded $2 \mathrm{~L} \mathrm{~min}^{-1}$. At flow rates lower than the $1.6 \mathrm{~L} \mathrm{~min}^{-1}$ optimum, conversion efficiency also decreased slightly. Although methanol may have been quantitatively converted to formaldehyde at these lower flows, some further catalytic decomposition of the formaldehyde or other loss process may have occurred during its longer residence in the reactor. Increasing the time intermediate species remain in contact with the active sites on the catalyst surface can lead to secondary reactions including the re-adsorption of the formaldehyde formed. The recent work by Kim et al. (2004) points out that formaldehyde can be subsequently oxidized to carbon monoxide at low flow rates, although other products may also be formed (Soares et al., 2005).

\subsubsection{Effect of carrier gas composition and total methanol concentration}

Conversion efficiency at a single reaction bed length, catalyst/quartz sand mixture, and catalytic converter temperature was tested using pure nitrogen rather than compressed air as the methanol standard dilution gas. The result of removing oxygen from the catalyst bed was a reduction in efficiency by about $42 \%$ (Fig. 3). This can be rationalised based on previously proposed mechanism for methanol to formaldehyde conversion, one path of which involves formation of a methoxy radical intermediate (Chu et al., 1997). In the absence of oxygen, no methoxy radical is formed and less formaldehyde is produced. However, formaldehyde is

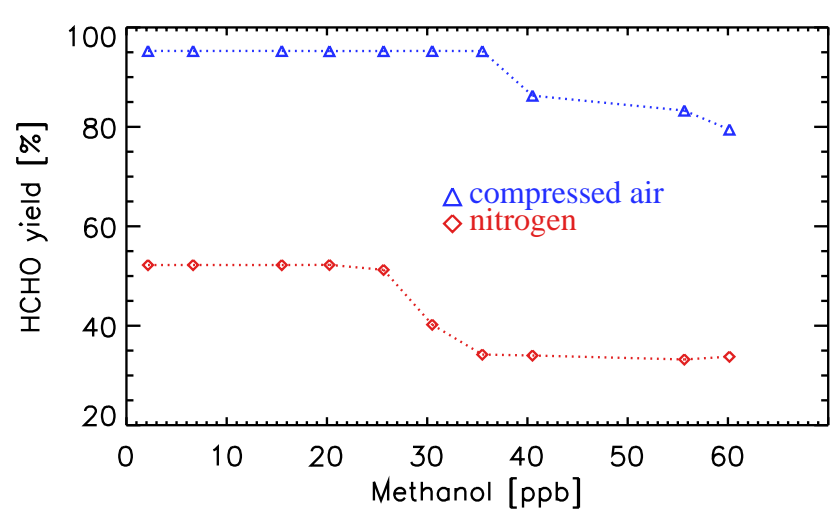

Fig. 3. The formaldehyde yield for methanol standard dilution in compressed air (blue) and nitrogen (red) as a function of methanol volume mixing ratio.

still produced and there is experimental evidence that oxygen from the lattice structure can participate in the methanol to formaldehyde oxidation reaction (Pernicone et al., 1969; Liberti et al, 1972). Thus, in the absence of oxygen in the reaction mixture, the catalyst surface becomes reduced, which decreases catalyst activity and selectivity.

It is reasonable to expect that at some high methanol mixing ratio, the exposed catalyst will become saturated with methanol molecules. At this point, further increase in methanol mixing ratio will not be accompanied by an increase in formaldehyde production and conversion efficiency will drop. Figure 3 shows the conversion effeciency as a function of methanol mixing ratio using a $12 \mathrm{~cm}$ reaction bed, a 1:4 ratio of catalyst/quartz sand, and a catalyst housing temperature of $345^{\circ} \mathrm{C}$. Efficiency decreased significantly beyond methanol mixing ratios of approximately $35 \mathrm{ppb}$ suggesting that additional catalyst mixture may be required in environments with very high methanol abundance. For more typical methanol mixing ratios (up to $30 \mathrm{ppb}$ ), the current catalytic converter configuration is sufficient.

For this configuration, Fig. 4 shows the linear relationship between methanol concentration and methanalyser response. The average $r^{2}$ (coefficient of determination) value for all calibration curves measured over a 6-month period was 0.986 suggesting a relative error of $1.4 \%$. Combining this error with the stated 5\% methanol standard uncertainty leads to a methanol measurement accuracy of better than $6 \%$ between 1 and $20 \mathrm{ppb}$.

Related to the maximum working concentration of the catalytic converter is degradation of performance over time or the gradual poisoning of the catalyst. Possible mechanisms for catalyst deactivation are discussed in Soares et al. (2001, 2003). For this work, repeated measurements of the conversion efficiency throughout a period of six months (data not shown) indicate little or no degradation in performance. However, possible impairment of catalytic converter performance during extended atmospheric sampling, where a larger variety of chemicals is sampled, remains to be tested. 


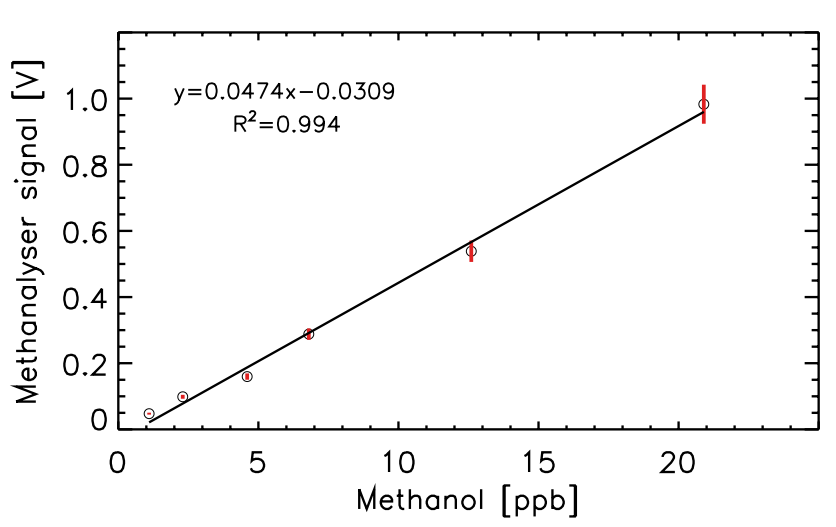

Fig. 4. Calibration curve of methanol mixing from 1 to $20.5 \mathrm{ppb}$ range at the estimated optimum catalyst temperature $\left(345^{\circ} \mathrm{C}\right)$ and contact time $(0.2 \mathrm{~s})$.

\subsubsection{Interference studies}

The catalyst, though promising for effective and selective methanol conversion, may also produce formaldehyde by the oxidation of other atmospheric trace gases. If methane, certain alkenes (e.g. isoprene), or another trace gas having comparable mixing ratio to methanol was to produce formaldehyde upon contact with the catalyst, methanol quantification could become problematic. Although a variety of studies have reported on the conversion of methane to methanol and formaldehyde using supported ferric molybdate catalysts at temperatures around $400-500^{\circ} \mathrm{C}$ and pressures from 160 bar (Brown et al., 1991; Chun and Anthony, 1993; Chellappa and Viswanath, 1995), there are no reports describing methane conversion to formaldehyde at temperatures below $400^{\circ} \mathrm{C}$. In studies where conversion is observed, catalyst surface areas were up to 50 times higher than those of the catalyst used here. The only literature we could find describing alkene reactions using a catalyst similar to that used in this work (ethene; Martin et al., 1993) did not report formaldehyde production. While possible reasons behind the selectivity of iron molybdate catalysts for methanol is discussed in general in Cheng et al. (1997), no other interference tests pertinent to our own studies were mentioned.

We tested the catalytic converter for possible interferences from methane and a variety of common atmospheric VOCs including isoprene, ethanol, benzene and acetone. For these experiments, either a standard tank containing methane (15 ppm, Linde, Germany) or a mixture of acetone, ethanol, benzene, and isoprene $(23.1 \mathrm{ppm} \pm 5 \%$, $5.82 \mathrm{ppm} \pm 3 \%, 10.7 \mathrm{ppm} \pm 2 \%$, and $6.59 \mathrm{ppm} \pm 10 \%$ respectively, Messer Griesheim, Germany) was diluted using synthetic air. Methane was diluted to final concentrations of $1.76 \mathrm{ppm}$ and $1.06 \mathrm{ppm}$ while the gas mixture was diluted to final isoprene concentrations of 2 and $55 \mathrm{ppb}$. These mixtures were then passed separately through the catalytic converter at a flow rate of $1.6 \mathrm{~L} \mathrm{~min}^{-1}$ under optimal catalytic

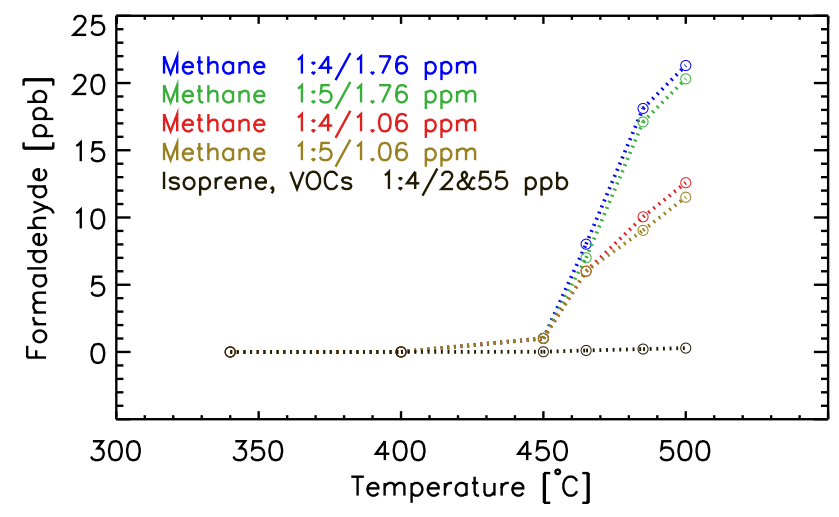

Fig. 5. Interference studies with methane and a mixture of common VOCs. Methanalyser response upon passage of methane, or the isoprene, ethanol, benzene and acetone standards diluted in synthetic air over the heated catalyst. The results show no interference for 1.06 and $1.76 \mathrm{ppm}$ methane up to $440^{\circ} \mathrm{C}$. The catalyst was tested using 2 and $55 \mathrm{ppb}$ of isoprene and a mixture of acetone, ethanol, and benzene. The methanalyser signal is essentially at the noiselevel below $450^{\circ} \mathrm{C}$.

methanol conversion conditions. The temperature of the catalytic converter housing was varied while monitoring the resulting formaldehyde mixing ratio, and the results of these experiments are illustrated in Fig. 5. No appreciable conversion of methane to formaldehyde was observed at a representative methane mixing ratio of $1.76 \mathrm{ppm}$ and catalyst temperatures up to $450^{\circ} \mathrm{C}$. Above $460^{\circ} \mathrm{C}$ increasing methane to formaldehyde conversion was observed, suggesting new energetic access to an efficient conversion process. None of the other four VOCs tested produced any measurable amounts of formaldehyde, even at mixing ratios significantly higher than would be expected for these compounds in the atmosphere. Although more thorough and comprehensive testing of interference is warranted, these initial results suggest that under the current temperature and flow conditions most atmospheric VOCs with mixing ratios comparable to methanol and with the potential to produce formaldehyde upon oxidation should exhibit no interference.

\subsection{Atmospheric measurements}

Atmospheric air sampled from the roof of the Institute of Environmental Physics building on the south side of the University of Bremen campus $\left(53^{\circ} 5^{\prime} \mathrm{N}, 8^{\circ} 49^{\prime} \mathrm{E}\right)$ was analysed for methanol and formaldehyde from 1 to 15 July 2004 . The results are shown in Fig. 6. Formaldehyde and formaldehydecorrected methanol mixing ratios for the complete period are presented. The respective meteorological data were provided by the Deutsche Wetterdienst (DWD) and were acquired from a weather station approximately $5 \mathrm{~km}$ to the Southwest. Although this period was unusually cold and rainy methanol still showed a pronounced diurnal cycle. Mixing ratios of methanol ranged from 1 to $5 \mathrm{ppb}$ with peak values at night. 


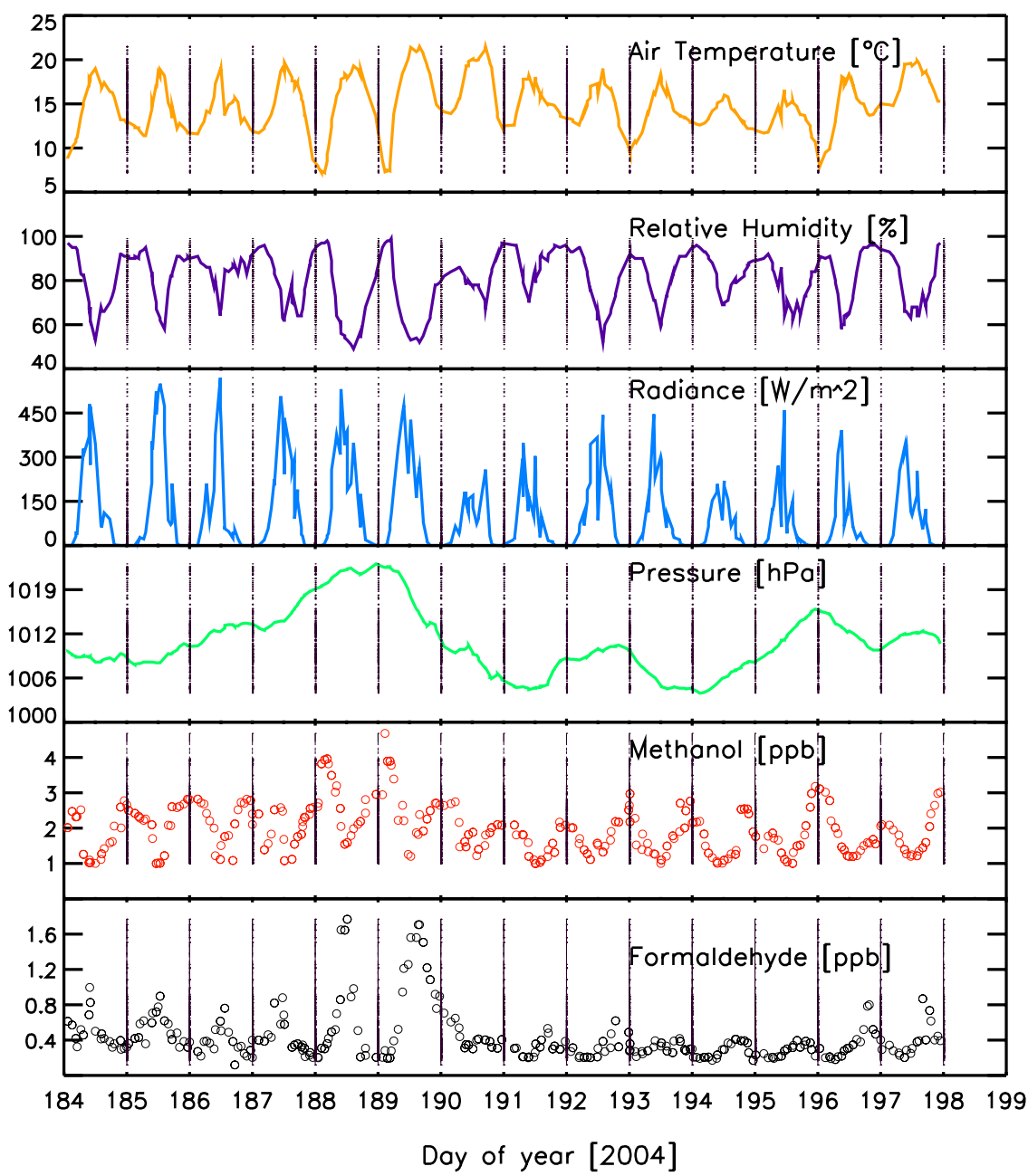

Fig. 6. Methanol and formaldehyde mixing ratios measured from outside the laboratory window along with meteorological data collected at a nearby weather station provided by the DWD during 1-15 July 2004.

Lower mixing ratios were observed during days 190-192 and 194-195. Both of these time periods were also associated with low atmospheric pressure. The nocturnal maxima were likely due to the prevention of efficient turbulent mixing in the nighttime boundary layer while methanol emissions continued, a common feature also found for methanol at other sites (Holzinger et al., 2001; Schade and Goldstein, 2001; Schade and Custer, 2004). We cannot find consistent features in the data that would suggest a significant contribution from anthropogenic sources such as car traffic. However, the measurement location was not well suited for such an analysis. Rather, we used back trajectory analysis with the NOAA HYSPLIT (HYbrid Single-Particle Lagrangian Integrated Trajectory) model (Draxler and Rolph, 2003) to analyse large-scale features. The model results indicate a frontal passage over Bremen over days 191 and 192. The change in air mass associated with passage of this low-pressure system was likely the origin of the decrease in methanol mixing ratio during this time.
Formaldehyde also showed a prominent diurnal cycle. Its mixing ratio ranged from 0.2 to $1.6 \mathrm{ppb}$ and peaked during midday. The midday maximum for formaldehyde is an expected result due to its photochemical source from the oxidation of hydrocarbons. Probably as a result of the relatively low ambient temperatures during this period, both methanol and formaldehyde mixing ratios were low when compared to previous studies. In an attempt to connect methanol and formaldehyde mixing ratios with the meteorological parameters, we carried out a simple factor analysis (Lamanna and Goldstein, 1999) whose results are given in Table 1. Interestingly, methanol showed a significant correlation with pressure and relative humidity while formaldehyde correlated better with solar irradiance and temperature.

As these methanol measurements are consistent with previous long-term measurements (Schade and Goldstein, 2001; Holzinger et al., 2001), they support the notion that the atmospheric methanol abundance is influenced more by the air mass origin and biogenic emissions than by anthropogenic emissions. 
Table 1. Factor analysis performed to find associations of methanol and formaldehyde mixing ratios with the meteorological parameters (loading values $<0.3$ omitted). Proportion variation defines the fraction of data explained by each factor. Cumulative variation is the sum of the proportion variation, indicating that nearly two thirds of observations are explained by these 2 factors. The chi square statistic is 15.06 on 4 degrees of freedom. The p-value is 0.00457 .

\begin{tabular}{lcc}
\hline & Factor 1 & Factor 2 \\
\hline Methanol & -0.533 & 0.639 \\
Formaldehyde & 0.501 & \\
Temperature & 0.852 & \\
Relative humidity & -0.932 & \\
Radiance & 0.693 & \\
Pressure & & 0.873 \\
\hline Sum square loadings & 2.646 & 1.30 \\
Proportion of variation & 0.441 & 0.218 \\
Cumulative variation & 0.441 & 0.659 \\
\hline
\end{tabular}

\section{Conclusions}

Gas phase conversion of methanol to formaldehyde using an iron molybdate catalyst was investigated as a simple and accurate way to measure atmospheric methanol using commercially available wet-chemical formaldehyde monitoring equipment. Maximum methanol to formaldehyde conversion efficiency of $95 \%$ was obtained using a catalyst bed temperature of $345^{\circ} \mathrm{C}$ and an air/catalyst contact time of less than $0.2 \mathrm{~s}$. This high efficiency remained unchanged over a period of several months of measurements for which the catalyst was used. Interference studies showed that neither methane nor a mixture of common atmospheric VOCs having significant ambient mixing ratios produced formaldehyde when passed over the Mo-Fe-O catalyst under optimum conditions. Though we have not studied all potentially interfering atmospheric VOCs, the fact that the combined high concentration mixture of a double 1-alkene (isoprene), an aromatic compound (benzene), an alcohol (ethanol), and a carbonyl (acetone) did not produce any significant formaldehyde signals, makes us confident that the catalyst is essentially bias-free for most atmospheric sampling applications.

We used the optimised reactor coupled with the wet chemical formaldehyde detector for atmospheric measurements of formaldehyde and methanol. Both methanol and formaldehyde showed diurnal features consistent with previous atmospheric measurements of these VOCs, providing further confidence into the capability of the method. This selective catalytic conversion technique shows great promise as a simple, efficient, transportable, and very affordable method for atmospheric methanol measurements.
Acknowledgements. We wish to thank P. Schumacher for her help with the electronic equipment, and Gerald Seiler for help with the data acquisition setup. This research was made possible by the Deutsche Forschungsgemeinschaft (DFG) under grant SCHA922/2-1.

Edited by: M. Ammann

\section{References}

Brown, M. J. and Parkyns, N. D.: Progress in the partial oxidation of methane to methanol and formaldehyde, Catal. Today., 8(3), 305-311, 1991.

Cárdenas, L., Brassington, D. J., Allan, B. J., Coe, H., Alicke, B., Platt, U., Wilson, K. M., Plane, J. M. C., and Penkett, S. A.: Intercomparison of formaldehyde measurements in clean and polluted atmospheres, J. Atmos. Chem., 37, 53-80, 2000.

Chellapa, A. S. and Viswanath, D.: Partial oxidation of methane using ferric molybdate catalyst, Ind. Eng. Chem. Res., 34, 19331940, 1995.

Cheng, W.-H.: Methanol and formaldehyde oxidation study over molybdenum oxide, J. Catalysis., 158, art. no. 0047, 477-485, 1996.

Chu, P. M, Thorn, W. J., Sams, R. L., and Guenther, F. R.: Ondemand generation of a Formaldehyde-in-air Standard, J. Res. Natl. Inst. Stand and Technol., 102(5), 559-568, 1997.

Chun, J. W. and Anthony, R. G.: Catalytic oxidation of methane to methanol, Ind. Eng. Chem. Res., 32, 259-263, 1993.

Clemitshaw, K. C.: A Review of Instrumentation and Measurement Techniques for Ground-Based and Airborne Field Studies of Gas-Phase Tropospheric Chemistry, Crit. Rev. Env. Sci. Tech., 34, 1-108, doi:10.1080/10643380490265117, 2004.

Dasgupta, P. K., Dong, S., Hwang, H., Yang, H.-C., and Genfa, Z.: Continuous liquid-phase fluorometry coupled to a diffusion scrubber for the real-time determination of atmospheric formaldehyde, hydrogen peroxide and sulphur dioxide, Atmos. Environ., 22, 949-963, 1988.

Dasgupta, P. K., Genfa, Z., Poruthoor, S. K., Caldwell, S., Dong, S., and Liu, S.-Y.: High-Sensitivity gas sensors based on gaspermeable liquid core wave guides and long-path absorbance detection, Anal. Chem., 70, 4661-4669, 1998.

Dasgupta, P. K., Genfa, Z., Li, J., Boring, C. B., Jambunathan, S., and Al-Horr, R.: Luminescence detection with a Liquid core waveguide, Anal. Chem., 71, 1400-1407, doi:10.1021/ac981260q, 1999.

de Gouw, J. A., Howard, C. J., Custer, T. G., Baker, B. M., and Fall, R.: Proton-transfer chemical ionization mass spectrometry allows real-time analysis of volatile organic compounds released from cutting and drying of crops, Environ. Sci. Tech., 2640 2648, 34, 2000.

de Gouw, J., Warneke, C., Karl, T., Eerdekens, G., van der Veen, C., and Fall, R.: Sensitivity and specificity of atmospheric trace gas detection by proton-transfer-reaction mass spectrometry, Int. J. Mass Spectrom., 223/224, 365-382, 2003.

Dong, S. and Dasgupta, P. K.: Solubility of gaseous formaldehyde in liquid water and generation of trace standard gaseous formaldehyde, Environ. Sci. Tech., 20, 637-640, 1986.

Dong, S. and Dasgupta, P. K.: Fast fluorometric flow injection analysis of formaldehyde in atmospheric water, Environ. Sci. Tech., 
21, 581-588, 1987.

Draxler, R. R. and Rolph, G. D., HYSPLIT (HYbrid Single-Particle Lagrangian Integrated Trajectory) Model access via NOAA ARL READY Website (http://www.arl.noaa.gov/ready/hysplit4.html), NOAA Air Resources Laboratory, Silver Spring, MD, 2003.

Fan, Q. and Dasgupta, P. K.: Continuous automated determination of atmospheric formaldehyde at the parts per trillion levels, Anal. Chem., 66, 551-556, 1994.

Galbally, I. E. and Kirstine, W.: The production of methanol by flowering plants and the global cycle of methanol, J. Atmos. Chem., 43, 195-229, 2002.

Gerberich H. R., Stautzenberger A. L, and Hopkins W. C.: Formaldehyde: Kirk-Othmer Encyclopedia of chemical technology, New York, John Wiley \& Sons, 231-250, 1980.

Gilpin, T., Apel, E., Fried, A., Wert, B., Calvert, J., Genfa, Z., Dasgupta, P. K., Harder, G. W., Heikes, B., Hopkins, B., Westberg, H., Kleindienst, T., Y-N. Lee, Zhou, X., Lonneman, W., and Sewell, S.: Intercomparison of six ambient $\left[\mathrm{CH}_{2} \mathrm{O}\right]$ measurement techniques, J. Geophys. Res., 102(D17), 21 161-21 188, 1997.

Goldan, P. D., Kuster, W. C., Fehsenfeld, F. C., and Montzka, S. A.: Hydrocarbon Measurements in the South eastern United States the Rural Oxidants in the Southern Environment (Rose) Program 1990, J. Geophys. Res., 100(D12), 25 945-25 963, 1995a.

Goldan, P. D., Trainer, M., Kuster, W. C., Parrish, D. D., Carpenter, J., Roberts, J. M., Yee, J. E., and Fehsenfeld, F. C.: Measurements of hydrocarbons, oxygenated hydrocarbons, carbon monoxide, and nitrogen oxides in an urban basin in Colorado: Implications for emission inventories, J. Geophys. Res., 100(D11), 22 771-22 783, 1995b.

Goldan, P. D., Kuster, W. C., and Fehsenfeld, F. C.: Nonmethane hydrocarbon measurements during the tropospheric $\mathrm{OH}$ photochemistry experiment, J. Geophys. Res., 102(D5), 6315-6324, 1997.

Heikes, B. G., McCully, B., Zhou, X., Lee, Y.-N., Mopper, K., Chen, X., Mackay, G., Karecki, D., Schiff, H., Campos, T., and Atlas, E.: Formaldehyde methods comparison in the remote lower troposphere during the Mauna Loa Photochemistry Experiment 2, J. Geophys, Res., 101, 14741-14 755, 1996.

Heikes, B. G., Chang, W., Pilson, M. E. Q., Swift, E., Singh, H. B.: Atmospheric methanol budget and ocean implication, Global Biogeochem. Cycles., 16(4), 1133, 1-13, doi:10.1029/2002GB001895, 2002.

Holzinger, R., Jordan, A., Hansel, A., and Lindinger, W.: Methanol measurements in the lower troposphere near Innsbruck $\left(47^{\circ} 16^{\prime} \mathrm{N} ; 11^{\circ} 24^{\prime} \mathrm{E}\right)$, Austria, Atmos. Environ., 35, 2525-2532, 2001.

Karl, T., Crutzen, P. J., Mandl, M., Staudinger, M., Guenther, A., Jordan, A., Fall, R., and Lindinger, W.: Variability-lifetime relationship of VOCs observed at the Sonnblick Observatory 1999 - estimation of HO-densities, Atmos. Environ., 35(31), 52875300, 2001.

Karl, T., Hansel, A., and Mark, T.: Trace gas monitoring at the Mauna Loa Baseline observatory using proton-transfer reaction mass spectrometry, Int. J. Mass Spectrom., 223(1-3), 527-538, 2003

Kelly, T. J., Callahan, P. J., Plell, J., and Evans, G. F.: Method development and field measurements for polar volatile organic compounds in ambient air, Env. Sci. Tech., 27, 1146-1153, 1993.
Kesselmeier, J., Ciccioli, P., Kuhn, U., Stefani, P., Biensenthal, T., Rottenberg, S., Wolf, A., Vitullo, M., Valentini, R., Nobre, A., Kabat, P., and Andrae, M. O.: Volatile organic compound emissions in relation to plant carbon fixation and the terrestrial carbon budget, Global Biogeochem. Cycles., 16(4), 1126 , doi:10.1029/2001GB001813, 2002.

Kim, T. H., Ramachandra, B., Choi, J. S., Saidutta, M. B., Choo, K. Y., Song, S. D., and Rhee, Y-W.: Selective oxidation of methanol to formaldehyde using modified Iron-Molybdate catalysts, Catal. Lett., 98(2,3), 161-166, 2004.

Kleindienst, T. E., Shepson, P. B., Nero, C. M., Arnts, R. R., Tejada, S. B., Mackay, G. I., Mayne, L. K., Schiff, H. I., Lind, J. A., Kok, G. L., Layrus, A. L., Dasgupta, P. K., and Dong, S.: An Intercomparison of Formaldehyde Measurement Techniques at Ambient Concentration, Atmos. Environ., 22(9), 1931-1939, 1988.

Lamanna, M. S. and Goldstein, A. H.: In situ measurements of $\mathrm{C}_{2}-\mathrm{C}_{10}$ volatile organic compounds above a Sierra Nevada ponderosa pine plantation, J. Geophys. Res., 104(D17), 21247 $21262,1999$.

Li, J., Dasgupta, P. K., Genfa, Z., and Hutterli, M. A.: Measurement of Atmospheric Formaldehyde with a Diffusion scrubber and light-emitting diode-liquid-core wave-guide based fluorometry, Field Anal. Chem. Tech., 5(1-2), 2-12, 2001.

Liberti, G., Pernicone, N., and Soattini, S.: Pulse microreactor study of methanol oxidation over $\mathrm{MoO}_{3}-\mathrm{Fe}_{2}\left(\mathrm{MoO}_{4}\right)_{3}$ catalyst, J. Catal., 27, 52-58, 1972.

Lindinger, W., Hansel, A., and Jordan, A.: Online monitoring of volatile organic compounds at pptv levels by means of protontransfer-reaction mass spectrometry (PTR-MS), Medical applications, food control and environmental research, Int. J. Mass Spectrom. Ion Processes, 173-181, 1998.

Martin, C., Martin, I., and Rives, I.: Fourier-transform infrared study of the oxidation of ethane on $\mathrm{MoO}_{3} / \mathrm{TiO}_{2}$ catalysts doped with alkali metals, J. Chem. Soc. Faraday. Trans., 89(22), 41314135, 1993.

Millet, D. B., Goldstein, A. H., Allan, J. D., Bates, T. S., Boudries, H., Bower, K. N., Coe, H., Ma, Y. L., McKay, M., Quinn, P. K., Sullivan, A., Weber, R. J., and Worsnop, D. R.: Volatile organic compound measurements at Trinidad Head, California, during ITCT 2K2: Analysis of sources, atmospheric composition, and aerosol residence times, J. Geophys. Res., 109(D23), S16, doi:10.1029/2003JD004026, 2004.

Nguyen, H. T., Takenaka, N., Bandow, H., and Maeda, Y.: Flow analysis method for determining the concentration of methanol and ethanol in the gas phase using the Nitrite formation reaction, Anal. Chem., 72, 5847-5851, 2000.

Prasad R. L. and Thakur S. N.: Monitoring air pollution using infrared photoacoustic spectra of organic vapours, J. Ind. Chem. Soc., 80(4), 341-344, 2003.

Pernicone, N., Lazzerin, F., Liberti, G., and Lanzavecchia, G.: On the mechanism of $\mathrm{CH} 3 \mathrm{OH}$ oxidation to $\mathrm{CH}_{2} \mathrm{O}$ over $\mathrm{MoO}_{3}$ $\mathrm{Fe}_{2}\left(\mathrm{MoO}_{4}\right)_{3}$ catalyst, J. Catal., 14, 239-243, 1969.

Qin, T., Xiaobai, X., Polák, T., Pacákova, V., Śtulik, K., and Jech, L.: A simple method for the trace determination of methanol, ethanol, acetone and pentane in human breath and in the ambient air by preconcentration on solid sorbents followed by gas chromatography, Talanta, 44(9), 1683-1690, 1997. 
Repond, P. and Sigrist, M. W.: Photoacoustic spectroscopy on trace gases with continuously tunable $\mathrm{CO}_{2}$ laser, Appl. Opt., 35(21), 4065-4085, 1996.

Riemer, D., Pos, W., Milne, P., Farmer, C., Zika, R., Apel, E., Olszyna, K., Kliendienst, T., Lonneman, W., Bertman, S., Shepson, and P., Starn, T.: Observations of nonmethane hydrocarbons and oxygenated volatile organic compounds at a rural site in the southwestern United States, J. Geophys. Res., 103, 28 111$28128,1998$.

Schade, G. W. and A. H. Goldstein.: Fluxes of oxygenated volatile organic compounds from a ponderosa pine plantation, J. Geophys. Res., 106(D3), 3111-3124, 2001.

Schade, G. W. and Custer, T. G.: OVOC emissions from agricultural soil in northern Germany during the 2003 European heat wave, Atmos. Environ., 38, 6105-6114, 2004.

Singh, H. B., Kanakidou, M., Crutzen, P. J., and Jacob, D. J.: High concentrations and photochemical fate of oxygenated hydrocarbons in the global troposphere, Nature, 378, 50-54, 1995.

Singh, H. B., Chen, Y., Tabazadeh, A., Fukui, Y., Bey, I., Yantosca, R., Jacob, D., Arnold, F., Wohlfrom, K., Atlas, D., Flocke, F., Blake, D., Blake, N., Heikes, B., Snow, J., Talbot, R., Gregory, G., Sachse, G., Vay, S., and Kondo, Y.: Distribution and fate of selected oxygenated organic species in the troposphere and lower stratosphere over the Atlantic, J. Geophys. Res., 105(D3), 37953805, 2000.

Singh, H. B., Salas, L. J., Chatfield, R. B., Czech, E., Fried, A., Walega, J., Evans, M. J. Field, B. D., Jacob, D. J., Blake, D., Heikes, B., Talbot, R. Sachse, G., Crawford, J. H., Avery, M. A., Sandholm, S., and Fuelberg, H.: Analysis of the atmospheric distribution, sources, and sinks of oxygenated volatile organic chemicals based on measurements over the Pacific during TRACE-P, J. Geophys. Res., 109(D15), S07, doi:10.1029/2003JD003883, 2004.
Snider, J. R. and Dawson, G. A.: Tropospheric light alcohols, carbonyls, and acetinitrile: concentrations in the southwestern United States and Henry's law data, J. Geophys. Res., 90, $3797-$ 3805, 1985.

Soares, A. P., Portela, M. F., Kiennemann, A., Hilaire, L., and Millet, J. M. M.: Iron molybdate catalysts for methanol to formaldehyde oxidation: effects of Mo excess on catalytic behavior, App. Catal. A, 206(2), 22-26, 2001.

Soares, A. P. V., Portela, M. F., Kiennemann, A., and Hilaire, L.: Mechanism of Deactivation of Iron-Molybdate Catalysts Prepared by Co precipitation and Sol-Gel Techniques in Methanol to Formaldehyde Oxidation, Chem. Eng. Sci., 58(7), 1315-1322, 2003.

Soares, A. P. V., Portela, M. F., and Kiennemann, A.: Methanol Selective oxidation to formaldehyde over Iron-Molybdate catalysts, Catal. Rev. Sci. Eng., 47(1), 125-145, 2005.

Tie, X., Guenther, A., and Holland, E.: Biogenic methanol and its impacts on tropospheric oxidants, Geophys. Res. Lett., 30(17), 1881, doi:10.1029/2003GL017167, 2003.

Vairavamurthy, A., Roberts J. M, and Newman, L.: Methods for determination of low molecular weight carbonyl compounds in the atmosphere: a reveiw, Atmos. Environ., 26A, 1965-1993, 1992.

Yokelson, R. J., Ward, D. E., Susott, R. E., Reardon, J., and Griffith, D. W. T.: Emission from smoldering combustion of biomass measured by open-path Fourier transform infrared spectroscopy, J. Geophys. Res., 102, 18 865-18 877, 1997.

Yokelson, R. J., Bertschi, I. T., Christian, T. J., Hobbs, P. V., Ward, D. E., and Hao, W. M.: Trace gas measurements in nascent, aged, and cloud-processed smoke from African savanna fires by airborne Fourier transform infrared spectroscopy (AFTIR), J. Geophys. Res., 108(D13), 8478, doi:10.1029/2002JD002322, 2003a. 